\title{
Flutemetamol F 18
}

National Cancer Institute

\section{Source}

National Cancer Institute. Flutemetamol F18. NCI Thesaurus. Code C90938.

A radiopharmaceutical containing flutemetamol, a thioflavin derivative of Pittsburgh compound $\mathrm{B}(\mathrm{PiB})$ labeled with the radioisotope fluorine F18 that can be used to detect beta-amyloid deposition upon positron emission tomography (PET). After intravenous administration of flutemetamol $\mathrm{F} 18$, the flutemetamol moiety selectively accumulates in and binds to cerebral fibrillar amyloid-beta in the brain. The fluorine F18 radioisotope moiety is detected using PET, which allows imaging and quantification of amyloid-beta density. Amyloid plaque deposition is linked to cognitive decline, including Alzheimer's disease, and may be linked to chemotherapy-induced cog nitive impairment $(\mathrm{ClCl})$. 